\title{
ARTículo
}

\section{La experiencia democrática y el sistema político peruano $(1980-2020)^{*}$}

\author{
The democratic experience and the Peruvian political system \\ (1980-2020)
}

Johel Miguel Pozo Tinoco

jpozotinoco@hotmail.com

Universidad Nacional Mayor de San Marcos

\section{RESUMEN}

La experiencia democrática en el Perú exige una revisión detallada de su definición puesta en práctica, así como las consecuencias de su uso. Por un lado, tenemos la noción procedimental que reduce la democracia al cumplimiento de reglas electorales; por otro, tenemos nociones más sustantivas que incluyen los conceptos de rendición de cuentas, oposición y calidad democrática, que exigen mayores ampliaciones sobre la primera noción procedimental, usada dentro de su sentido común. El caso peruano sitúa a la democracia en un marco histórico más reciente (1978-1980) en el que se logró cumplir un criterio de ampliación de derechos civiles a una gran parte de la ciudadanía, pero mantuvo intactos los problemas de desigualdad social que convierten a la ciudadanía y a las elecciones en meras apariencias de los valores atribuidos al sistema democrático. Un segundo momento importante se halla luego del 2001, cuando el final de un régimen autoritario no significó la eliminación de la corrupción y de situaciones de conflicto que están vigentes actualmente dentro de la democracia actual.

Palabras clave: Democracia; procedimiento; rendición de cuentas; corrupción; élites.

\section{ABSTRACT}

The democratic experience in Peru requires a detailed review of the definition of democracy in practice, as well as the consequences of its use. On the one hand, there is a procedural notion that reduces democracy to compliance with electoral rules; on the other hand, there are more substantive notions that include the concepts of accountability, opposition and democratic quality, which require further expansions on the first procedural notion, used within its common sense. The Peruvian experience places democracy in a more recent historical framework (1978-1980) in which it was possible to meet a criterion of extending civil rights to a large part of the citizenship, but kept intact the problems of social inequality that turn citizens and elections into mere appearances of the values attributed to the democratic system. A second important moment took place after 2001, when the end of an authoritarian regime did not mean the elimination of corruption and conflict that are in force within today's democracy.

Keywords: Democracy; procedure; accountability; corruption; elites.

\footnotetext{
* El presente artículo forma parte del marco teórico utilizado en el desarrollo actual de una tesis sobre la calidad de la democracia en gobiernos subnacionales en el Perú.

(C) Los autores. Este artículo es publicado por ISHRA, Revista del Instituto Seminario de Historia Rural Andina de la Facultad de Ciencias Sociales de la Universidad Nacional Mayor de San Marcos. Este es un artículo de acceso abierto, distribuido bajo los términos de la licencia Creative Commons Atribucion - No Comercia Compartir Igual 4.0 Internacional. (http://creativecommons.org/licenses/by-nc-sa/4.0/) que permite el uso no comercial, distribución y reproducción en cualquier medio, siempre que la obra original sea debidamente citada.
} 


\section{Introducción}

La historia política del Perú, desde la formación de la república, ha tenido un sinuoso recorrido que ha desembocado actualmente en la valoración de la democracia como un destino deseable. Pero en el discurso de los actores políticos se ostenta una retórica de lo democrático que lo convierte en una entidad abstracta casi sin tiempo, origen y menos aún contenido conceptual. El presente artículo aspira situar la experiencia democrática dentro de un marco histórico de acuerdo con los criterios teóricos que la definen. Se realizará una revisión del concepto de democracia y de las ampliaciones que ha realizado la ciencia política, luego se evaluará los criterios de definición de la democracia con el sistema político peruano, para finalmente proponer un diagnóstico de los elementos pendientes más importantes.

Partimos de una postura sustantiva de la democracia, la cual se define por criterios adicionales como la rendición de cuentas, el sistema de oposiciones, la calidad democrática y los derechos sociales. Por ende, partimos de la premisa de que la experiencia democrática requiere de un papel central del Estado para sentar la infraestructura institucional. Consideramos insuficiente la definición de la democracia solo por la existencia de un sistema de elecciones, pues incluso un sistema de elecciones transparente puede ser compatible con regímenes autoritarios o de una pobre calidad democrática y de rendición de cuentas.

Adicionalmente proponemos una evaluación de la experiencia democrática peruana y del sistema actual con base en los hechos más importantes en materia de historia política y en la percepción de la población.

\section{La democracia como concepto itinerante: procedimiento y contenido}

Lejos de utilizar referencias clásicas, recurriremos primero a la noción de democracia surgida en plena Guerra Fría, ya que nos sitúa directamente en la definición histórica más reciente del plano internacional. Este contexto internacional es importante porque a partir del clivaje capitalismosocialismo, los diferentes actores políticos, institucionales y académicos sentaron las bases de lo que consideran como lo democrático.

En ese sentido, Samuel Huntington es quien desarrolló una postura muy precisa de lo que significa la democracia. A su juicio:

Aparecen serios problemas de ambigüedad e imprecisión cuando se define la democracia en términos de autoridad o de propósitos, y usamos en este estudio una definición basada en procedimientos. En otros sistemas de gobierno, las personas se convierten en líderes por razones de nacimiento, número, riqueza, violencia, alianza, aprendizaje, selección o examen. El procedimiento principal de la democracia consiste en la selección de líderes a través de elecciones competitivas por parte de las personas gobernadas por ellos. (Huntington, 1994, pp. 19-20)

Esta postura denominada democracia procedimental será considerada como punto de partida para entender la lógica de los bloques geopolíticos y la formación de valores dentro de una ideología bien definida que resultó victoriosa al final de la Guerra Fría.

Esta noción procedimental alimentó y sigue alimentando tanto a las políticas de entidades supranacionales como la Organización de Naciones Unidas (ONU) como a los diferentes Estados, reflejándose esto en los planes y programas a largo plazo que se fijan como ejes orientadores de desarrollo político institucional' ${ }^{1}$.

1 Uno de los documentos internacionales que apela a este concepto (y otros) es la Carta Democrática Interamericana de 2001 que se redactó a partir de las experiencias de autoritarismos como el gobierno de Alberto Fujimori. Aunque también incluye una noción 
Pero esta postura de la democracia procedimental encierra otras premisas que se apartan del sentido clásico que podría definir a la democracia como el gobierno del pueblo y para el pueblo. En ese sentido, Huntington pone límites al gobierno, a la participación y a la comunidad política. Por lo tanto, lo democrático, según Huntington, se restringe a la existencia de un sistema de elecciones para gobernantes nacionales y subnacionales. Este procedimiento de elección de líderes implica, a su vez, restringir las demandas a partir de un gobierno centralizado que cobra autonomía o discrecionalidad para mandar. Además, se pone énfasis en limitar la demanda de los diferentes grupos sociales para no poner en riesgo el sistema mismo por su estabilidad tanto política como económica.

[...] la operación efectiva de un sistema político democrático generalmente requiere cierta medida de apatía y no participación por parte de algunos individuos y grupos. En el pasado, cada sociedad democrática ha tenido una población marginal, de mayor o menor tamaño, que no ha participado activamente en la política. Los grupos sociales marginales, como en el caso de los negros, ahora se están convirtiendo en participantes plenos en el sistema político. Sin embargo, el peligro de sobrecargar el sistema político con demandas que extiendan sus funciones y socave su autoridad aún permanece. Por lo tanto, una menor marginación por parte de algunos grupos debe ser reemplazada por una mayor autolimitación por parte de todos los grupos. (Crozier, Huntington y Watanuki, 1975, p. 114) [Traducción nuestra]

Esta noción ha sido ampliada a partir de las observaciones a algunas oleadas democratizadoras señaladas por el mismo Huntington. Podemos notar que se pone mucho énfasis en el riesgo de sobrecargar el sistema (overload), por ejemplo, con un excesivo gasto público que vuelve inestable al sistema por conducir a una recesión que redunda en una inestabilidad política².

El final de la Guerra Fría tuvo un vencedor, pero la noción de democracia construida por el bloque capitalista, en el que se sitúa Huntington, ha sufrido muchos reveses demostrables a partir de casos específicos en los que el procedimiento de elecciones ha llevado a la formación de nuevas formas de autoritarismo y corrupción. Por ello, el procedimiento por sí mismo no basta para delimitar lo democrático, pero es un buen punto de partida para comprender los cambios conceptuales y los requisitos que hacen democrático a un sistema político. Por lo pronto, queda sentado que, para esta perspectiva, la causa necesaria de la democracia es la existencia de un sistema de elecciones. Frente a esta perspectiva realizaremos algunas ampliaciones.

Una primera ampliación para comprender lo democrático lo podemos hallar en Tilly (2010). En un sentido histórico, la democracia no es una realidad empírica unívoca sino un proceso en permanente cambio. Por ello, Tilly precisa que existen procesos de democratización y desdemocratización. No existe un destino hacia la democracia, los procesos pueden ser de avances o retrocesos, siempre determinados por la dinámica política de cada momento. Esto implica abrir un repertorio de requisitos históricos o históricamente apreciables. Para Tilly, estos requisitos son dimensiones históricas, las cuales presentamos a continuación:

\footnotetext{
de democracia constitucional, el criterio fundamental de las libertades para elegir representantes se ha consolidado como el más importante. Los recientes debates en torno al sistema de elecciones en Venezuela o Bolivia, por ejemplo, demuestran el interés por valorar lo democrático a partir de las garantías institucionales para cumplir este aspecto procedimental.

2 El reciente conflicto en Ecuador a partir de la eliminación del subsidio del combustible es una muestra de esta sobrecarga. Esta situación ocasionada por el aumento del gasto público y la incapacidad de la productividad ha conducido a la política de paquetazos que produjo la respuesta violenta de la población. Pero la receta del FMI, en línea con los conceptos de lo político y democrático, pueden conducir a una recesión, mayor dependencia y la posibilidad de aumentar la desigualdad. La propuesta de un refinanciamiento de la deuda, reduciendo el déficit fiscal por medio de la reducción del gasto público, tiene como premisa fundamental limitar las demandas de la población democráticamente incluidas en procesos de elecciones (indígenas).
} 
Tabla 1. Dimensiones de los procesos de democratización de un sistema político.

\begin{tabular}{|l|l|}
\hline \multicolumn{1}{|c|}{ Dimensiones } & \multicolumn{1}{c|}{ Definición } \\
\hline Amplitud & $\begin{array}{l}\text { Incremento (o disminución) en la parte de la población que dispone de derechos legalmente practicables para } \\
\text { comunicar quejas a los altos funcionarios acerca de la actuación gubernamental }\end{array}$ \\
\hline Igualdad & $\begin{array}{l}\text { Declive (o emergencia) en el número de distintas categorías legales que definen derechos y obligaciones de } \\
\text { diferentes segmentos de la población vis-à-vis el Estado }\end{array}$ \\
\hline $\begin{array}{l}\text { Protección } \\
\text { Consulta mutua } \\
\text { vinculante }\end{array}$ & $\begin{array}{l}\text { Incremento (o disminución) de la porción de todas las demandas de los ciudadanos relativas a la denegación de } \\
\text { beneficios ordenados legalmente que resultan en el libramiento de tales beneficios }\end{array}$ \\
\hline
\end{tabular}

Fuente: Tilly (2010, p. 101)

Esta ampliación permite entender que no es suficiente que existan elecciones libres y que todos los ciudadanos participen en ellas para elegir representantes nacionales o locales. También es importante notar que, durante el tiempo de gobierno de los regímenes, los criterios de lo democrático pueden ser mayores porque no solo implican respetar las reglas electorales sino también los derechos políticos y sociales, aunados a una conducta de rendición de cuentas junto al respeto del marco constitucional ${ }^{3}$.

A mayor amplitud, igualdad y protección de la ciudadanía, así como mayor consulta mutua vinculante, mayor democratización de un sistema político en un sentido histórico. La amplitud implica la desaparición de población marginada de derechos civiles y políticos, como el derecho al voto, por ejemplo. La igualdad implica la desaparición de ciudadanías de segundo o tercer orden ${ }^{4}$. La protección implica el Estado de derecho y el respeto de los derechos civiles y políticos. Y la consulta mutua vinculante se relaciona con la capacidad de rendición de cuentas, cumplimiento de propuestas y el diálogo con la sociedad civil. Ver la tabla 1 para observar la amplitud de cada una de estas cuatro dimensiones.

Esta ampliación que retomamos de los estudios de Tilly nos permite ver el contenido de la democracia en un sentido mucho más amplio que el de un sistema de elecciones para representantes nacionales. $\mathrm{O}$ si se prefiere, podemos hablar de un procedimiento simple (electoral) inmerso en un proceso compuesto (democratización histórica). De esta forma, podemos notar cómo la noción de la democracia es itinerante, transitando entre un momento coyuntural de elección de representantes y otro momento - no menos importante- que implica el tiempo de vida de los gobiernos.

Una forma complementaria para observar los procesos de democratización consiste en considerar cómo los poderes fácticos (centros de poder) van cediendo terreno frente al papel del Estado y de las reglas de juego, con lo que se disminuye la arbitrariedad de las élites y el abuso.

\footnotetext{
3 La Carta Democrática Interamericana establece una relación muy estrecha entre orden constitucional y orden democrático, a tal punto que la ruptura del primero conlleva a la ruptura del segundo. Pero esto sugiere que la conducta de un régimen puede afectar al sistema político mismo, tal como se comprueba con el gobierno de Alberto Fujimori, cuyos actos de corrupción implicaron una transformación del Estado y con ello también del sistema político.

4 Este criterio resulta importante porque implica la desaparición de un sistema de elecciones censitario, como es el que podemos hallar en casi toda la historia del Perú. Este sistema de elecciones, si bien permite una apertura de nuevos ciudadanos, los ubica en un rango de menor relevancia tal como lo expresó el expresidente Alán García a propósito del conflicto entre comuneros de la Amazonía y la policía el 2009 en Bagua: "Ya está bueno. Estas personas no tienen corona, no son ciudadanos de primera clase. 400 mil nativos no pueden decirnos a 28 millones de peruanos: tú no tienes derecho de venir por aquí" (Mendoza, 2011).
} 
Los procesos fundamentales que promueven la democratización en todas las épocas y lugares [...] consisten en incrementar la integración de las redes de confianza de la política pública, incrementando la separación de la política pública de la desigualdad de rango y disminuyendo la autonomía de los principales centros de poder de la política pública. (Tilly, 2010, p. 56)

Resulta muy sugerente que Tilly llame la atención sobre la disminución de la autonomía de los poderes fácticos (centros de poder) como una dimensión importante para definir un proceso de democratización. Esto nos conduce a otro camino teórico que aborda la teoría de las élites y la teoría de la corrupción. Esta breve digresión nos permitiá situar lo democrático en un sentido sociológico necesario, puesto que el sistema político no se sostiene solo con valores sino con la acción de individuos y organizaciones sociales.

\subsection{Primera digresión: Las élites y el sistema político}

Antonny Giddens (2006) se refería al mundo social como una estructura estructurada y estructurante. Estructurada por la acción de los individuos y organizaciones. Y estructurante porque moldea los límites de la acción de los mismos individuos y organizaciones que pugnan por adaptarse o cambiar su propia realidad.

La existencia de las élites es inevitable y empíricamente puede comprobarse su participación en todo sistema social. Gaetano Mosca (2004) insistía en que en toda sociedad existe una minoría organizada que prevalece sobre una mayoría desorganizada, de tal suerte que las élites siempre detentan el poder y se adaptan al sufragio universal, convirtiéndolo -en cada época- en una ilusión, puesto que los mismos postulantes a elecciones provienen de las élites o se financian gracias a ellas.

A su vez, Pareto (1980) señala que una élite organizada se beneficia de una masa ignorante, aunque es inevitable una competencia entre élites nacientes y otras en declive. Por lo tanto, las transiciones políticas están signadas por la lucha entre élites políticas (leones versus zorros), élites económicas (rentistas versus especuladores), y élites intelectuales (hombres de fe versus intelectuales). El cambio es lo único permanente en las dinámicas políticas y conceptualmente se trata de fijar con definiciones que solo pueden ser útiles en un sentido clasificatorio.

Michels (1991), por su parte, tuvo interés en profundizar el estudio de las élites y su relación con las organizaciones de masa y los regímenes que son compatibles con una clasificación que él ofreció. Dentro de su enfoque, toda organización social contiene una élite, incluso los partidos políticos, sin importar su bandera ideológica. Para Michels, existe una suerte de compatibilidad entre un tipo de élite y un tipo de régimen (ver tabla 2). Las élites abiertas son aquellas más liberales o tolerantes frente a las masas y sus demandas, mientras que las élites cerradas son aquellas más autoritarias e intolerantes frente a la conducta de las masas.

Tabla 2. Clasificación de élites y régimen político

\begin{tabular}{|l|l|}
\hline \multirow{2}{*}{ Eipo de élite } & Tipo de régimen \\
\hline \multirow{4}{*}{ Élites cerradas } & Democrático \\
\cline { 2 - 2 } & Liberal \\
\hline & Autocrático \\
\cline { 2 - 2 } & Aristocrático \\
\cline { 2 - 2 } & Oligárquico \\
\hline
\end{tabular}

Fuente: Michels (1991) 
Esto nos ofrece un mayor panorama para comprender por qué Tilly y otros politólogos agregan más criterios para definir lo democrático. La razón de ello se encuentra en la dinámica política y la composición de clases sociales en pugna en toda sociedad.

Para el caso peruano aún se mantiene pendiente una investigación amplia de las élites y su composición como, por ejemplo, la élite militar que goza de derechos exclusivos sobre vivienda, educación, empleo y justicia, como se comprueba con la existencia del Fuero Militar Policial (ente autónomo de justicia) $)^{5}$.

A esta digresión de la teoría de las élites podemos añadir algunas observaciones a partir de los planteamientos de José Carlos Mariátegui sobre el asunto. La primera de ellas es el contenido ideológico de la que son portadoras. Mientras mayor claridad y sentido ideológico pueden ofrecer, mayor será esa potencia política.

Las verdaderas élites intelectuales operan sobre la historia revolucionando la conciencia de una época. El verbo necesita hacerse carne. El valor histórico de las ideas se mide por su poder de principios o impulsos de acción... Es absurdo hablar de un drama de las élites. Una élite en estado de ser compadecida, por este solo hecho deja de ser una élite. Para la historia no existen élites relegadas. La élite es esencialmente creadora... Por obvias razones, las élites del capitalismo en los últimos tiempos, ha estado principalmente compuesta de jefes de empresa, de grandes comerciantes, industriales y financistas (Mariátegui, 1987 [1928], p. 50)

La segunda observación es que este poder creativo de las élites no puede ser aislado de los estudios de sistemas políticos, donde precisamente se orientan hacia algo que ideológicamente se va forjando en el debate político y la dinámica que implica consensos y conflictos entre individuos y organizaciones.

Estas observaciones son importantes porque nos sugieren abordar a todas las élites a partir de su participación en la vida política. El caso de la élite militar es un caso paradigmático en el Perú puesto que han sido diversos militares en retiro los que han sido ministros de diferentes gobiernos, combinando un rol técnico especializado en materia de seguridad y defensa, incluso un expresidente fue miembro de las Fuerzas Armadas. Asimismo, también cumplen un rol político y académico que contribuye con la dinámica política.

Del mismo modo, se puede incluir a la élite religiosa compuesta por miembros de las diferentes iglesias que abiertamente han contribuido políticamente con diferentes gobiernos y han tenido representantes en el parlamento, combinando su labor legislativa con la expresión de su ideología ${ }^{6}$. Han convocado movilizaciones masivas, se han manifestado en favor o en contra de políticas públicas, cuentan con medios de comunicación y líderes de opinión reconocidos. Actualmente, incluso una agrupación de base religiosa como el Frente Popular Agrícola del Perú (FREPAP) ha logrado conseguir representantes en el Congreso de la República y ya cuenta con experiencia en diferentes gobiernos municipales de la Amazonía.

\footnotetext{
5 Esto nos conduce al inevitable debate de si el poder civil debe gobernar al poder militar. Independientemente de la postura, una investigación sobre el impacto de esta élite en la democracia del Perú resulta importante. En ese sentido, importa conocer la contribución de la existencia de un fuero autónomo en la centralidad del Estado y su rol al reducir la capacidad de los otros centros de poder o poderes fácticos. En un sentido radical, podríamos plantear la siguiente cuestión: ¿Qué clase de sistema político democrático admite un ente autónomo de justicia para una clase social en particular?

6 Por ejemplo, el movimiento conservador Con Mis Hijos No Te Metas y el partido fujimorista Fuerza Popular tuvieron coincidencias importantes en la oposición al gobierno de Pedro Pablo Kuczynski y luego al de Martín Vizcarra sobre políticas educativas específicas en torno a la equidad de género. Las coincidencias llegaron incluso a manifestaciones públicas y digitales que demuestran la participación de colectivos religiosos en la política parlamentaria y la correlación de fuerzas entre los poderes del Estado.
} 
Militares, religiosos y otras élites que componen la clase política ameritan un estudio pormenorizado sobre la dinámica política que tejen, así como su influencia en el sistema político en su conjunto.

\subsection{Segunda digresión: Corrupción política}

Una segunda digresión importante es acerca de la teoría de la corrupción política. En el caso peruano, contamos con un estudio histórico pormenorizado de Alfonso Quiroz en el que define a la corrupción

[...] como el mal uso del poder político-burocrático por parte de camarillas de funcionarios, coludidos con mezquinos intereses privados, con el fin de obtener ventajas económicas o políticas contrarias a las metas del desarrollo social mediante la malversación o el desvío de recursos públicos, junto con la distorsión de políticas e instituciones (Quiroz, 2013, p. 30)

La distorsión de políticas e instituciones se halla indisolublemente ligada a las garantías institucionales que requiere un sistema democrático para funcionar, respondiendo a las demandas de la ciudadanía y en beneficio colectivo. El deterioro de las instituciones, en cierto sentido, implica una no-democracia por dos razones. La primera, porque la existencia de camarillas e intereses privados forman parte de una dinámica extrapolítica que es opuesta al sentido representativo básico del sistema democrático. Y, en segundo lugar, porque la corrupción, al ser un acto ilegal, es opuesta a cualquier sentido de rendición de cuentas o transparencia que también implica el sistema democrático.

Francisco Durand realiza una ampliación importante del concepto de corrupción a partir de un debate sobre la captura del Estado en democracia. Se precisa a las corporaciones como principal actor que ejerce la captura del Estado

Para entender este tipo [de "captura" en democracia], es necesario un enfoque que, yendo más allá de la corrupción, identifique varios mecanismos de influencia (financiación de campañas, lobbys en la sombra y "puerta giratoria") con el fin de explicar su impacto en las iniciativas legales, pero no limitándose a ellas, en tanto también se toma en cuenta la implementación de políticas. Cabría preguntarse qué sucede con regímenes semidemocráticos o dictatoriales y cómo ello implica cambios de estrategia de los actores para recurrir a los mecanismos más persuasivos, los arriba citados u otros, en los cuales probablemente el soborno sea más importante (Durand, 2016, p. 16).

Esto permite ver ambos actores involucrados en la corrupción: funcionarios como miembros de la burocracia y empresarios como miembros de una clase social que capturan al Estado. Y es precisamente esta conducta como clase social la que no puede ser excluida en el análisis del respaldo o la oposición a un régimen y un sistema político. ${ }^{7}$

El empresariado también puede actuar políticamente por medio de partidos cuando esas agrupaciones cumplen un rol en definir quién ocupa el Estado y quién influye en el Congreso, lo que generalmente ocurre en democracias. Por su postura a favor de la empresa privada y la vinculación al mercado mundial, son las agrupaciones conservadoras las que tienden lógicamente a atraerlos y representar mejor sus intereses. Sin embargo, razones prácticas, como quién está en el poder, o las

7 Un tema de investigación importante al respecto es la participación de la Confederación Nacional de Instituciones Empresariales Privadas (CONFIEP) durante la década de 1990. Al respecto puede consultarse Flores (2015) 
diferentes cuotas políticas de los partidos, empujan a los empresarios a jugar a la política del acomodo con fuerzas no conservadoras. Los partidos también suelen ser útiles en caso de dictaduras que no permiten la influencia empresarial en el Estado. Les sirven para manifestar su oposición y buscar alternativas de régimen político (provocar o apoyar un golpe; insistir en una transición democrática). También ocurre que los empresarios pueden prescindir de los partidos cuando gobiernos o gobernantes autoritarios establecen relaciones directas cercanas y positivas con firmas y gremios (Durand, 2004, p. 19).

Esta participación de los empresarios como clase, implica una estructura de participación y de lo que Tilly denominó "autonomía de los centros de poder" [económico]. Es decir, aquello que el Estado debe reducir para una democratización de un sistema político. Además, como toda estructura, esta puede ser representada esquemáticamente mediante la figura 1:

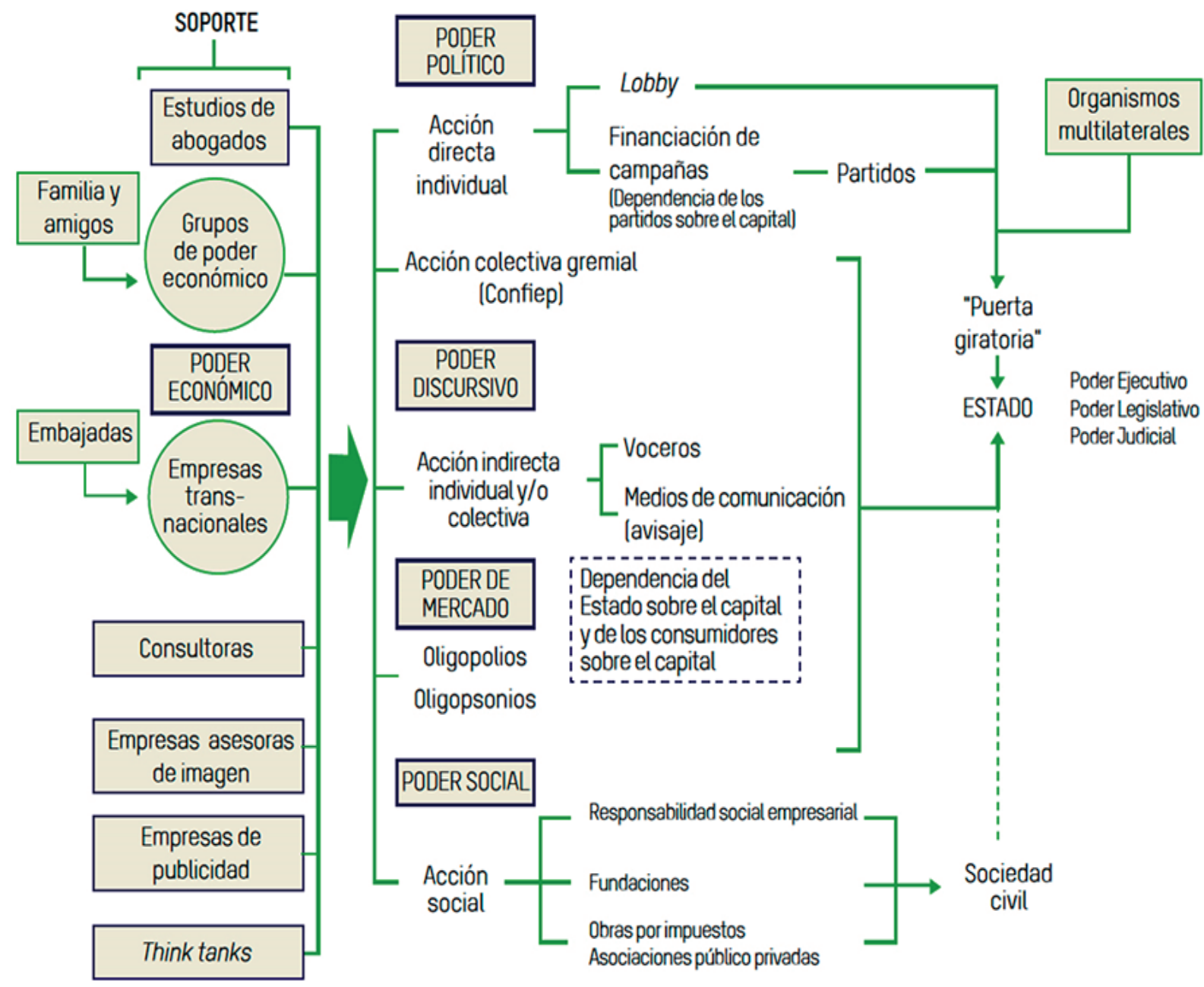

Figura 1. Poderes de la élite económica y proyección hacia el Estado y la sociedad Fuente: Durand (2016, p. 27)

Con la reciente investigación judicial masiva en América Latina sobre el financiamiento político de la empresa constructora Odebrecht, queda mucho material académico para actualizar 
los conceptos de corrupción, captura del Estado en democracia, lobbys y la definición de la democracia misma.

Un enfoque como el que proponemos [enfoque de poder multidimensional] pasa entonces por comprender: 1) la naturaleza económica y organizativa de una empresa con múltiples y crecientes poderes, que se expresan en su modelo de negocios; 2) sus conexiones políticas y sociales organizadas en torno a un modelo de influencias (donde ambos modelos son desarrollados desde su país de origen, home country, y luego exportados y adaptados localmente al host country; y 3) la posibilidad de capturar el Estado usando los dos modelos, lo que genera múltiples consecuencias económicas, institucionales, políticas sociales y reputacionales (Durand, 2019, p. 34).

Podemos ver a la corrupción política en su sentido legalista, pero también es importante notar que la corrupción requiere de elementos externos al sistema político. En el caso peruano, la judicialización de los casos de corrupción de obras públicas se halla en pleno desarrollo, que incluye la participación de empresarios nacionales y extranjeros. Si entendemos que la corrupción política se refiere a cualquier política pública, entonces podemos entender que existen campos como el de la salud, educación, comercio, etc. que se hallan en medio del campo de acción de funcionarios públicos corruptos y agentes externos corruptores. El impacto de la corrupción en el Perú sobre el sistema político y la calidad democrática aún no ha sido evaluado, por lo que se abre una línea muy amplia de estudio de historia política contemporánea.

No se puede realizar una evaluación de un sistema político sin abordar paralelamente el comportamiento de las élites y sus características. Del mismo modo, la corrupción es un problema permanente de todo sistema que influye en toda política pública y la calidad democrática. Estas dos digresiones sirven para presentar el tema de manera muy general y proponer su inclusión en todo análisis de sistema político.

\section{La democracia como modelo}

Volviendo al asunto de la definición de la democracia. Otra ampliación del concepto, que a la vez resulta clasificatorio, se puede hallar en Robert Dahl (2012) quien precisa una cantidad de criterios para definirla.

1. Participación efectiva (oportunidades iguales para participar políticamente).

2. Igualdad de voto (todos los votos deben considerarse iguales).

3. Comprensión ilustrada (capacidad para que cada miembro tenga el suficiente conocimiento de asuntos públicos).

4. Control de la agenda política (capacidad para deliberar los asuntos de gobierno).

5. Inclusión de los adultos (ampliación de la ciudadanía sin jerarquías) ${ }^{8}$.

Como ya se hizo mención, existe un momento electoral y otro momento de gobierno, ambos momentos permiten agregar un contenido de requisitos muy amplio al concepto de lo democrático. Dicho en otras palabras, la ampliación conceptual de lo democrático implica

8 Aplicar una medición empírica de estos criterios para nuestra realidad implica abrir una línea de análisis muy valiosa, ya que primero se tendría que delimitar los momentos de medición, pues mientras más coyuntural o estructural sea esta, entonces la calidad del contenido de la democracia y sus resultados podría ofrecer resultados más interesantes. 
distinguir la conquista y el ejercicio del poder (Cameron y Sosa, 2013) y también concatenar estos dos aspectos en torno a un sentido histórico como lo formuló Tilly.

Pero también es importante distinguir o separar analíticamente: a) El momento de la dinámica política y su duración, y b) los actores sociales en coyunturas específicas. Por ello, son importantes los aportes de Robert Dahl para delimitar la democracia según criterios más amplios que incluyen la participación. Por ello también se precisa que "el gobierno democrático se caracteriza fundamentalmente por su continua aptitud para responder a las preferencias de sus ciudadanos, sin establecer diferencias políticas entre ellos" (Dahl, 2009, 13).

Para Dahl, existe un triple movimiento entre liberalización (debate público), representación (participación) y democratización institucional (garantías y derechos). Mientras mayor liberalización, representación y democratización institucional a lo largo del tiempo, mayor democratización del sistema político en general ${ }^{9}$. Este triple movimiento puede ser representado esquemáticamente mediante la figura 2.

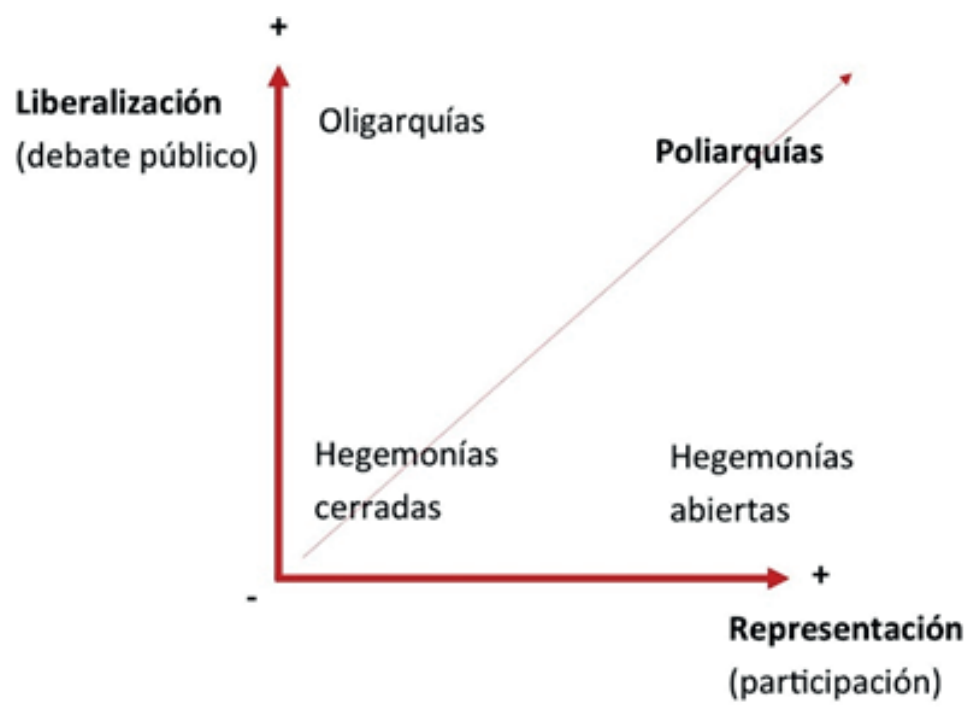

Figura 2. Liberalización, representación y poliarquía

Fuente: Dahl (2009, pp. 17-18)

Metodológicamente, podemos clasificar a los regímenes según su grado de liberalización y representación, de tal manera que los regímenes con mayor grado empírico de estos dos criterios se clasifican dentro de las poliarquías, que son las formas empíricas más próximas a las democracias. Por ello, "cabría considerar las poliarquías como regímenes relativamente (pero no completamente) democráticos; o, dicho de otra forma, las poliarquías son sistemas sustancialmente liberalizados y popularizados, es decir, muy representativos a la vez que francamente abiertos al debate público" (Dahl, 2009, 18). Lo opuesto a las poliarquías son los diferentes tipos de hegemonías.

Esto permite abrir otra línea de investigación relacionada a la forma y contenido del debate público, sus características, las instituciones involucradas y la inevitable tensión ideológica (o la ausencia de ella). Si consideramos a los medios de comunicación como actores centrales

9 Aunque Dahl establece una diferencia metodológica entre la democracia como ideal, que se define por el cumplimiento de requisitos, y la poliarquía como realidad existente e imperfecta en la que algunos criterios se cumplen de manera desigual empíricamente. La poliarquía resulta ser un concepto clasificador de los regímenes y sistemas políticos que tienen mayor liberalización, representación, Estado de derecho y también la existencia de oposiciones. 
del debate público, no podemos aislarlos de la lucha por el poder ni de la pertenencia o no de determinadas clases o élites. Si consideramos otras formas del debate público como las redes de internet, contamos con antecedentes que nos permitirían emitir algunas premisas con base a una primera mirada comparativa. En ese sentido, la experiencia de les gilets jeunes resulta oportuno no solo como movimiento social urbano sino por su capacidad para generar contenido y debate independiente de los mass media ${ }^{10}$.

\section{Los especímenes híbridos}

Tomando como referencia teórica, en una forma sintetizada, los aportes de Tilly y Dahl podemos pasar de las oleadas democratizadoras a la teoría de las transiciones a la democracia. Finalizada la Guerra Fría y en un nuevo contexto que Fukuyama señala como el fin de la historia, pareciese que dicho fin se tuvo que postergar porque no apareció un sistema político democrático definitivo.

Guillermo O’Donnell (1994, 2004) y O’Donnell, Iazzetta y Quiroga (2011) aportaron con la teoría de las transiciones hacia la democracia, mostrando lo que él denominó especies intermedias. Regímenes que no son totalmente democráticos ni totalmente autoritarios, pese a ser elegidos mediante sistema de elecciones. Estos regímenes híbridos permitieron reevaluar lo que se define como sistema democrático y en qué momento existen como tal.

[...] las democracias delegativas se basan en la premisa de quien sea que gane una elección presidencial tendrá el derecho a gobernar como él (o ella) considere apropiado, restringido solo por la dura realidad de las relaciones de poder existentes y por un período de funciones limitado constitucionalmente. El presidente es considerado como la encarnación del país, principal custodio e intérprete de sus intereses. Las políticas de su gobierno no necesitan guardar ninguna semejanza con las promesas de su campaña [...] (O’Donnell et al., 1994, pp. 59-60) [Traducción nuestra].

Entre los conceptos más resaltantes para señalar estos regímenes híbridos también contamos con el de autoritarismo competitivo (Levitsky y Way, 2004). Este concepto alude a regímenes que nacen de procesos de elecciones (satisface el criterio de democracia procedimental), pero que durante su gobierno se alteran las reglas de juego o abiertamente las inclinan a su favor para controlar la prensa, eliminar la oposición y perpetuarse en el poder.

El autoritarismo competitivo debe diferenciarse, por un lado, de la democracia, y por otro, del autoritarismo absoluto. Los regímenes democráticos modernos cumplen con cuatro criterios mínimos: 1) Los cuerpos ejecutivo y legislativo son elegidos a través de elecciones abiertas, libres y justas; 2) virtualmente todos los adultos tienen derecho a votar; 3) los derechos políticos y las libertades civiles, incluida la libertad de prensa, la libertad de asociación y la liberad de criticar al gobierno sin represalias, son ampliamente protegidos; 4) las autoridades elegidas tienen autoridad real para gobernar y no están sujetas al control tutelar del ejército o a los líderes religiosos. Aunque los regímenes democráticos plenos a veces pueden violar uno o más de estos criterios, estas violaciones no logran impedir seriamente los desafíos democráticos a los funcionarios gubernamentales. En otras palabras, no alteran fundamentalmente el campo de juego entre el gobierno y la oposición.

10 Gilets jeunes fue como se denominó al movimiento de protestas iniciadas en octubre de 2018 en París contra el aumento del precio de combustibles, y que rápidamente se propagó hacia otras localidades europeas como Bélgica y Alemania. Este movimiento tiene muchas particularidades que se pueden encontrar en Dumay (2019) y en Gilets jaunes. Des clés pour comprendre (2018). 
Al contrario, en los regímenes autoritarios competitivos las violaciones de estos criterios son lo suficientemente frecuentes y serias para crear un campo de juego desigual entre gobierno y oposición. Aunque se den con regularidad elecciones sin fraude, los funcionarios abusan constantemente de los recursos delEstado, no ofrecen a la oposición un cubrimiento adecuado de los medios, persiguen a los candidatos de la oposición y a sus seguidores y, en algunos casos, manipulan los resultados de las elecciones. De igual modo, periodistas, políticos de la oposición y otros críticos del gobierno pueden ser espiados, amenazados, perseguidos o arrestados. También miembros de la oposición pueden ser enviados a prisión, exilados o -con menor frecuencia- incluso asaltados, acosados o asesinados. Regímenes caracterizados por estos abusos no pueden ser llamados democráticos (Levitsky y Way, 2004, pp. 161-162).

Las precisiones de Levitsky y Way nos acercan a la teoría de la corrupción y la captura del Estado antes mencionada y su papel dentro de la dinámica política.

Pero si los regímenes autoritarios competitivos no alcanzan a ser democracias, tampoco llegan a ser autoritarismos absolutos. Aunque los funcionarios en los regímenes autoritarios competitivos puedan manipular frecuentemente las normas democráticas formales, no pueden eliminarlas o reducirlas a una mera fachada. En vez de violar abiertamente las normas democráticas (por ejemplo, prohibiendo y reprimiendo a la oposición y a los medios), los funcionarios prefieren utilizar el soborno, la cooptación y otras formas más sutiles de persecución, como el uso de las autoridades de impuestos, judiciales condescendientes $\mathrm{u}$ otros organismos del Estado para acosar, perseguir o presionar "legalmente" un comportamiento cooperativo de los críticos (Levitsky y Way, 2004, p. 162).

Por lo tanto, la democracia se convierte en un concepto itinerante porque transita entre el momento electoral, la conducta del régimen y la estructura del Estado. El sistema de elecciones para elegir representantes nacionales y subnacionales hace democrático ese momento. La conducta del régimen respetando las leyes, sometiéndose a una rendición de cuentas (accountability) y permitiendo y promoviendo la oposición, hace democrática la conducta de un régimen. La permanencia de la autonomía de los poderes del Estado, el marco jurídico para los derechos civiles y políticos, así como la transparencia institucional hacen democrático un sistema político nacional.

\section{La calidad de la democracia}

Se puede aventurar una explicación para la variedad de especies de democracias a nivel mundial: la diferencia entre la calidad de los componentes democráticos permite distinguir democracias más consolidadas de otras en proceso de consolidación, y de algunas en proceso de degeneración. La bibliografía señalada hasta aquí se puede sintetizar en dos publicaciones de corte metodológico ${ }^{11}$. El primero corresponde al aporte de Leonardo Morlino $(2012,2014)$ con respecto a la calidad de la democracia entendida en una triple forma: calidad del procedimiento, calidad del contenido y calidad de los resultados, las cuales se resumen en la tabla 3.

11 Podría resultar interesante incluir a Soria (2015) para abordar un fenómeno continental definido como democracias con libertades disminuidas, que es un modo diferente de abordar estos regímenes híbridos, pero desde el enfoque emanado del marco teórico de la Carta Democrática Interamericana que sirve de pilar metodológico de las instituciones internacionales para valorar la ausencia o presencia de democracia en un país. 
Tabla 3. Dimensiones de la democracia y calidad democrática

\begin{tabular}{|c|c|}
\hline Dimensiones & Tipo de calidad \\
\hline 1) Rule of law, o Estado de Derecho & \multirow{5}{*}{$\begin{array}{l}\text { Calidades } \\
\text { procedimentales }\end{array}$} \\
\hline 2) Accountability electoral, o rendición de cuentas electoral & \\
\hline $\begin{array}{l}\text { 3) Accountability institutional, o rendición de cuentas entre instituciones o interinstitucional (por ejemplo, } \\
\text { entre gobierno y parlamento, jefe de Estado y/o tribunal supremo) }\end{array}$ & \\
\hline 4) Competencia entre partidos y de otra naturaleza & \\
\hline 5) Participación de diferentes actores, ciudadanos incluidos & \\
\hline 6) Respeto pleno de los derechos que pueden ampliarse en la realización de las diversas libertades & \multirow{2}{*}{$\begin{array}{l}\text { Calidades sustantivas } \\
\quad \text { (contenido) }\end{array}$} \\
\hline 7) Progresiva ampliación de una mayor igualdad política, social y económica & \\
\hline $\begin{array}{l}\text { 8) Responsiveness, o responsividad, es decir, la satisfacción de los ciudadanos y la sociedad civil en general } \\
\text { derivada de la capacidad de respuesta del gobierno y sus instituciones. }\end{array}$ & $\begin{array}{l}\text { Calidad de los } \\
\text { resultados }\end{array}$ \\
\hline
\end{tabular}

Fuente: Morlino (2012, pp. 10-11)

A su vez, a partir de múltiples estudios empíricos se establece una clasificación de los tipos de democracia tomando en cuenta la complejidad de los momentos electorales, momentos de gobierno y de los resultados de cada régimen.

Una democracia efectiva puede resultar cuando existen garantías reales de libertad y una implementación de igualdad que se adhiere estrechamente a los mínimos requisitos necesarios, pero con un Estado de derecho fuerte. Una democracia responsable es una que también está caracterizada por niveles de libertad e igualdad que alcanzan un umbral mínimo, pero que exhiben un respeto satisfactorio por la rendición de cuentas. Una democracia participativa está caracterizada por ciudadanos y grupos que tienen la voluntad, disponibilidad y oportunidades institucionales para participar no únicamente en las elecciones, sino también mediante canales que van más allá de la representación política tradicional e incluyen formas de democracia directa, asociaciones, y oportunidades para la deliberación. Una democracia competitiva, abierta y efectiva requiere un pluralismo de los actores políticos y al menos la garantía efectiva de las libertades negativas, con una consecuente alternancia de las élites en el poder, también como un efecto de información justa y una distribución más igualitaria de los recursos de poder, como por ejemplo acceso a los medios de comunicación, habilidad y dinero. Una democracia completamente legitimada está caracterizada por el fuerte y amplio apoyo de una sociedad civil satisfecha que ofrece un firme testimonio de la responsividad de dicho régimen. Las democracias libres o igualitarias pueden variar dependiendo de sus características procedimentales, pero cada una exhibe una fuerte afirmación de alguno de los dos valores. En ellas puede coexistir la responsividad pero no es un requisito definicional. Para completar el cuadro analítico, también se puede hipotizar una democracia perfecta, en la cual todas las dimensiones están presentes en un grado muy alto. Asimismo, la expresión "en un grado muy alto" llama la atención de la fundamental e incorregible indeterminación empírica de cada dimensión. Su significado puede ser entendido de diferentes maneras en periodos distintos o por personas, líderes y ciudadanos con valores distintos (Morlino, 2012, 37-38) [énfasis agregado]

La calidad del contenido de un sistema democrático permite clasificar diversos tipos de democracia. En el nivel de calidad mínima-aceptable hallamos al tipo de democracia efectiva y 
en el otro espectro, en el nivel de cumplimiento máximo-demostrable, encontramos algo cercano a la democracia perfecta. Entre uno y otro espectro podemos encontrar diferentes grados de poliarquías.

Por otra parte, los aportes de Larry Diamond por sintetizar esta clasificación de regímenes híbridos o pseudodemocracias son importantes. Para el 2001 nos presenta un panorama copado de conceptos clasificatorios que podrían ser de utilidad para ver la densidad de "nuevas especies", como diría O'Donnell, que aparecen y que escapan de todas las definiciones de democracia por el cumplimiento heterogéneo de sus requisitos o dimensiones.

Una de las características más impactantes del "último período" de la tercera ola ha sido el crecimiento sin precedentes de los regímenes que no son claramente democráticos ni convencionalmente autoritarios. Si utilizamos un estándar estricto de democracia, que incluye no solo las elecciones democráticas sino también la protección sólida de las libertades civiles bajo un fuerte imperio de la ley, la proporción de regímenes intermedios se incrementa porque muchas de estas nuevas "democracias" de la tercera ola son "iliberales" (Diamond, 2004, p. 124)

La distribución de esta variedad de regímenes se puede observar a continuación:

Tabla 4. Tipos y frecuencias de régimen a finales de 2001

\begin{tabular}{|l|c|c|c|}
\hline Tipos de régimen & $\begin{array}{c}\text { Países con más de un millón } \\
\text { de habitantes N (\%) }\end{array}$ & $\begin{array}{c}\text { Países con menos de un } \\
\text { millón de habitantes N (\%) }\end{array}$ & Todos los países N (\%) \\
\hline $\begin{array}{l}\text { Democracia liberal } \\
\text { (calificación Freedom House 1-2.0) }\end{array}$ & $45(30)$ & $28(66.7)$ & $73(38.0)$ \\
\hline Democracia electoral & $29(19.3)$ & $2(4.8)$ & $31(16.1)$ \\
\hline Regímenes ambiguos & $14(9.3)$ & $3(7.1)$ & $17(8.9)$ \\
\hline Autoritarismo competitivo & $19(12.7)$ & $2(4.8)$ & $21(10.9)$ \\
\hline Autoritarismo electoral hegemónico & $22(14.7)$ & $3(7.1)$ & $25(13.0)$ \\
\hline Autoritarismo políticamente cerrado & $21(14)$ & $4(9.5)$ & $25(13.0)$ \\
\hline Total & $150(100)$ & $42(100)$ & $192(100)$ \\
\hline
\end{tabular}

Fuente: Diamond (2004, p. 124)

Esta clasificación, representada en la tabla 4, resulta pertinente porque incluye no solo los diferentes tipos de democracia sino también los diferentes tipos de autoritarismo en un momento dado a nivel internacional. Cabe precisar que todo autoritarismo se caracteriza por la ausencia de calidad en los componentes democráticos, aunque ello no significa la ausencia de legitimidad o de una dinámica política que le sea favorable ${ }^{12}$.

\section{Propuesta cronológica y clasificatoria del sistema político peruano}

Bajo la luz de todo lo señalado anteriormente es posible afirmar que la experiencia de la democracia en el Perú no es lineal ni unívoca, sino que ha transitado por diferentes momentos de mayor o menor calidad democrática, e incluso de experiencias autoritarias. Una periodificación histórica sintetizada que tome en consideración el tipo de Estado y el tipo de régimen (López 1997; Levitsky y Way 2004; Cameron y Sosa 2013; O'Donnell 1994) podría ser la siguiente:

12 El régimen político cubano desde su revolución en 1969 se clasifica como un autoritarismo cerrado de partido único. Este es uno de los principales referentes de la antípoda teórica de una democracia, incluso de una democracia efectiva, aquella que cumple los requisitos mínimos de calidad democrática. 


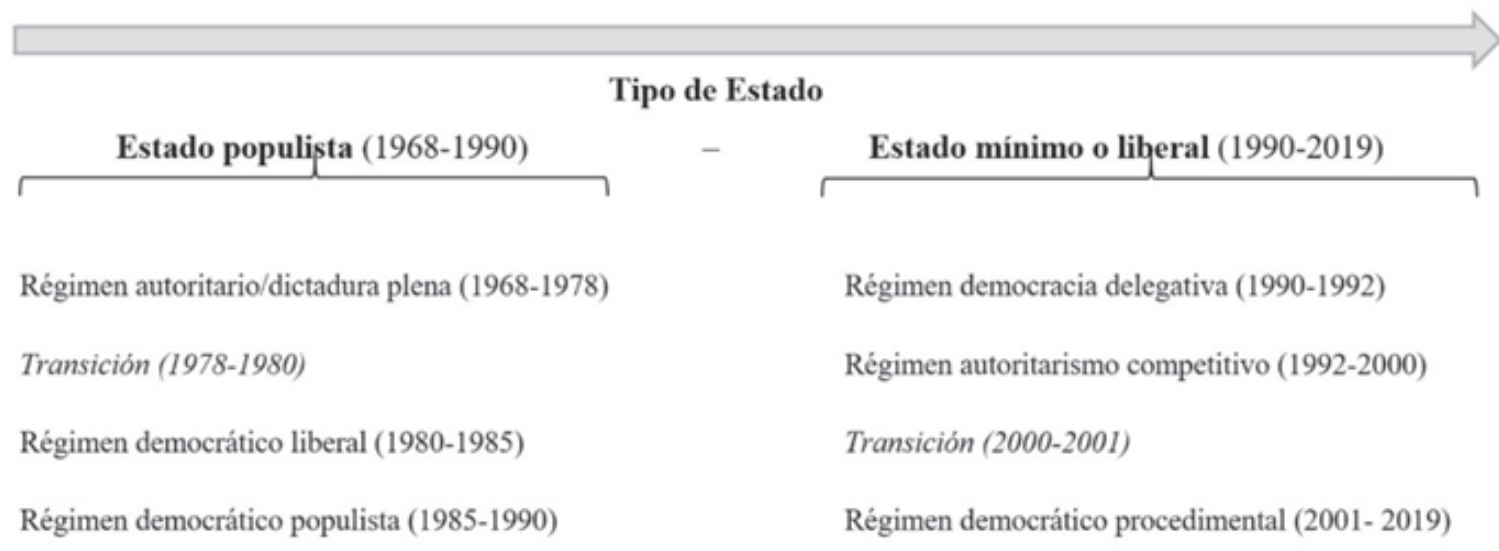

Figura 3. Periodización del tipo de Estado y régimen en el Perú (1968-2019)

Fuente: Elaboración propia

Esta periodización, representada en la figura 3, es una propuesta clasificatoria que permite, de manera directa, fijar el año de 1980 como un hito importante para la ampliación sustantiva de la democracia en el Perú. Paradójicamente, este hito se fija con una transición condicionada por un régimen autoritario. La razón principal para fijar este hito, y no ajena a polémica, es porque la Constitución Política de 1979 amplió la ciudadanía a un sector de la población históricamente marginado: los analfabetos ${ }^{13}$. Esta Constitución, en su título VII Disposiciones generales y transitorias, Disposición quinta, numeral 7 y 8, declara que sea el Jurado Nacional de Elecciones el que ajuste la viabilidad del voto de analfabetos con exoneración de multa por inasistencia por única vez en el proceso de 1980.

Podríamos señalar que, desde el inicio de la República hasta el momento previo a esta reforma constitucional, el voto que predominó fue el censitario y que, a pesar de la legalización del voto femenino en 1955, recién en la década de 1980 podemos hablar del cumplimiento total del criterio de amplitud y un cumplimiento parcial del criterio de igualdad formulados por Tilly (véase tabla 1). Del mismo modo, podemos señalar que a partir de esta reforma se satisfacen en gran medida los criterios 1) participación efectiva, 2) igualdad de voto, y 5) inclusión de los adultos, formulados por Dahl.

El grado de constatación empírica exigiría una evaluación comparativa con la estadística de procesos electorales anteriores y posteriores que no se puede realizar en el presente artículo pero que sugiere un estudio más pormenorizado del mismo: el padrón electoral en perspectiva histórica desde los criterios de democratización.

Podemos enfrentar esta propuesta de fecha de inicio de la democracia contra una objeción empírica importante, puesto que el 2005 mediante la Ley 28480 se modificaron los artículos 31 y 34 de la Constitución de 1993, ampliando el derecho al voto a los miembros de las Fuerzas Armadas y de la Policía Nacional ${ }^{14}$. Esto conllevó un aumento de 138156 nuevos electores en el proceso electoral de 2006, según padrón. Esta sería una razón objetiva por la que algunas personas podrían considerar el inicio de una experiencia democrática plena el año 2006.

13 Otro grupo, no menos importante, también fue el de los peruanos radicados en el extranjero que fueron incluidos en el padrón electoral de 1980

14 Ley de reforma de los artículos $31 .^{\circ}$ y $34 .^{\circ}$ de la Constitución Política del Perú, sobre el voto de los miembros de las Fuerzas Armadas y de la Policía Nacional. 
Pese a esta objeción, existe una razón estructural e histórica que convierte a la ampliación del voto a los analfabetos de 1980 en un punto de inflexión. Desde décadas precedentes, la desigualdad reposaba fuertemente en la distinción entre campo y ciudad, siendo el campo en el que mayormente se concentraban los índices de analfabetismo y pobreza. Precisamente, durante el régimen militar de Velasco Alvarado, lo rural fue el objetivo de una de las reformas agrarias más radicales de nuestra historia reciente, lo que condujo a la eliminación de una clase social completa: los gamonales. Con ello, culminaron provisionalmente aquellas incursiones democratizadoras de las que hablaba Sinesio López (1997), que precisamente tejieron el espíritu de los debates de Mariátegui, Haya de la Torre, Hildebrando Castro Pozo, José María Arguedas, etc. La ampliación de derechos civiles a esta extensa masa de analfabetos podría definirse sin atrevimiento como el zeitgeist o el nudo de una mentalidad colectiva que pudo ser representada en una de las reformas constitucionales más importantes en términos de democratización, a pesar de que fue formulada al final de un régimen autoritario.

Podemos decir que políticamente desaparece una clase social: la oligarquía, y simultáneamente se consolidó, mediante el derecho a voto, una clase social: el campesinado.

El3 de octubre de 1968 la oligarquía perdió sus representantes políticos en el gobierno. Poco después perdió su base económica: los complejos agroindustriales, el control del comercio exterior, la banca, etc. En años posteriores, el poder de los grupos subordinados a dicha oligarquía se redujo aún más: grandes y medianos propietarios en la costa, gamonales serranos y comerciantes de la sierra enfrentaron el avance de las empresas estatales. El poder, antes oligárquico, se concentra principalmente en el Estado, el cual amplía también su margen de acción al redefinir sus relaciones con el capital imperialista (Pease, 1977, p. 51).

Sumado a ello, la participación campesina, conformada en gran medida por una población analfabeta, logró establecer una dinámica propia a partir de nuevas organizaciones campesinas como la Confederación Nacional Agraria, la Confederación Campesina del Perú, entre otras. Esta dinámica produciría a lo largo del tiempo una nueva composición de actores sociales, relaciones y lo que Enrique Mayer (2017) nombró como cuentos feos de la reforma agraria.

Aun así, este punto de inicio es imperfecto puesto que los criterios de protección y consulta mutua vinculante no se cumplen a cabalidad. Una muestra de la desprotección de los ciudadanos frente a las arbitrariedades de los gobiernos y las fuerzas represivas son los reiterados casos de ciudadanos muertos en protestas medioambientales mucho más recientes como los de Bagua (2009), Conga (2011), Espinar (2012), Tía María (2013), entre otros ${ }^{15}$. Todos estos conflictos estuvieron relacionados con comunidades campesinas o indígenas y la participación de intereses privados como el de la minería. Del mismo modo, el escenario de guerra durante el periodo de conflicto armado interno que abarcó la década de los 80 y parte de la década de los 90 , condujo a una contracción de la participación ciudadana debido al asesinato de líderes políticos, perpetrado por organizaciones subversivas y grupos paramilitares de los gobiernos de Alan García y Alberto Fujimori. En términos generales, la apertura formal de ciudadanía a los analfabetos aún mantiene asuntos pendientes debido a la precariedad de la protección de la seguridad individual frente a lo que fue violencia subversiva y a la violencia estatal aún vigente.

Del mismo modo, los criterios de comprensión ilustrada y control de la agenda política, formulados por Dhal, resulta debatible puesto que la definición de una comprensión ilustrada

15 Las fechas corresponden a los años de mayor conflicto y con saldos de muertos y heridos. La mayor parte de los conflictos medioambientales tienen una duración extendida de muchos años, algunos vigentes hasta hoy. 
implica para Dhal la existencia de debate público, a lo que podemos agregar el papel de la prensa como actor que transmite las opiniones públicas, pero también como actor ligado a los centros de poder o poderes fácticos. Este debate público en el Perú se halla sumido en un escenario de permanente conflicto o tensión entre el gobierno y las oposiciones que se forman en el tiempo y en cada escenario. Si bien se puede plantear como una premisa que durante la década de los 80 ocurrió un auge político y propagandístico de organizaciones políticas urbanas, la década de los 90 contrasta por el documentado hecho de la eliminación del debate público auspiciado por el régimen de Alberto Fujimori y el trastocamiento o instrumentalización de los medios de comunicación en una orgía periodística sin precedentes ${ }^{16}$. En ese sentido, se puede plantear que el debate público está íntimamente relacionado al control de la agenda política, por lo que hasta el 2001 lo que constatamos es una precariedad de este criterio de comprensión ilustrada exigida por Dhal.

Finalmente, se puede hallar una objeción importante al inicio de la democracia en el Perú, en la relación existente entre los gobiernos y las oposiciones. Entendiendo el sistema político como algo más que autoridad y obediencia, y entendiendo también a la democracia como algo más que elecciones, podemos señalar que un aspecto central para el diagnóstico del sistema político peruano se halla en esta relación.

Dhal plantea tres axiomas con respecto a los gobiernos que toleran la oposición:

a) La probabilidad de que un gobierno tolere la oposición aumenta en la medida que disminuye el precio de dicha tolerancia; b) La probabilidad de que un gobierno tolere la oposición aumenta en la medida en que aumenta el precio de suprimirla y c) En la medida en que el precio de la supresión exceda al precio de la tolerancia, mayores son las oportunidades de que se dé un régimen competitivo (Dhal, 2009, p. 24).

El caso peruano, como muchos otros, descalifica como sistema que transita históricamente a una poliarquía ${ }^{17}$. Los saldos de muertes en conflictos medioambientales de los últimos 19 años podrían sugerir una insuficiencia del sistema democrático en el tiempo que trasciende los gobiernos, pese a que en los momentos electorales se cumplen los estándares legales y el clima de paz para que sea más recurrente. La represión de protestas en el Perú tiene una forma casi inmediata luego de la protesta, postergándose las negociaciones o mesas de diálogo cuando la violencia se desborda. Si ampliamos esto a conflictos sociales generados por protestas laborales, universitarias, entre otras, podemos suponer que el papel represivo del Estado peruano opera con mayor velocidad que los mecanismos democráticos de inclusión del debate público sobre asuntos de gobierno nacional o local. Precisamente ese es el quid del asunto en la teoría de Dhal. Mientras un régimen no permita la aparición de oposiciones o su libre participación, nos alejamos más del campo clasificatorio de las poliarquías y del ideal de la democracia.

A esto cabe agregar que para Dhal existen siete condiciones que favorecen la existencia de una poliarquía: "la secuencia histórica, grado de concentración en el orden económico, nivel de desarrollo socioeconómico, desigualdades, segmentación subcultural, control extranjero

\footnotetext{
16 Existe un antecedente histórico importante sobre un episodio de la prensa: la vulgaridad y el juego político que cumplía el periódico El Comercio a inicios del periodo republicano (véase Basadre 1983, volumen II, p. 286). De manera metafórica podemos decir que la difusión de la prensa chicha durante el fujimorismo representó una nueva orgía periodística del escándalo, los psicosociales y la mediocridad televisiva.

17 Dhal excluye al Perú, al menos de su edición de 1989, de ser una poliarquía. El Perú no se acerca al espectro de la poliarquía, ni por procesos evolutivos, ni por colapso o derrocamiento revolucionario del antiguo régimen, ni por conquista militar, ni por ser un Estado dependiente, ni tras la lucha por la independencia nacional (Dhal, 2009, pp. 48-49). Pero deja a libre interpretación que existe una mayor probabilidad de llegar a una poliarquía por procesos de evolución pacífica.
} 
y creencias de los activistas políticos" (Dhal, 2009, p. 39) ${ }^{18}$. Todo esto amerita ampliar varios estudios sobre la relación entre los gobiernos y sus oposiciones en el Perú, que dejamos como una tarea pendiente. A partir de dicha ampliación se puede revisar la teoría de la poliarquía, su método de análisis y clasificación de la democracia.

Siendo estrictos con los planteamientos de Tilly y Dhal, si tuviéramos que definir la democracia por el cumplimiento de todos esos criterios, el sistema político peruano actual aún se hallaría en proceso de reconocimiento parcial de derechos civiles a comunidades en la Amazonía, por lo que ni siquiera el mapa político coincide con el mapa de ciudadanía real. Pero en un sentido un poco más flexible, que admite la polémica, podríamos decir que luego de la Asamblea Constituyente de 1978-1979, se pudo sentar las bases de una reforma importante de apertura a la participación efectiva que sigue su marcha. Pero queda pendiente que, según el criterio de Morlino sobre la calidad de la democracia con énfasis en sus resultados, la mayor muestra de insuficiencia de la democracia se halla en los mapas de conflictos activos que presenta la Defensoría del Pueblo y los sondeos de opinión pública que no dejan en buen lugar de valoración a la democracia.

\section{La percepción de la democracia peruana en perspectiva comparada}

En los términos de Morlino sobre calidad de la democracia relativa a los resultados, nos vemos sumidos en una enorme insatisfacción generalizada, no solo hacia uno u otro gobierno, sino hacia el mismo sistema en general. El 51\% del sondeo del Latinobarómetro en el Perú registra la calificación de una "democracia con grandes problemas", tal como podemos observar en la figura 4, donde el Perú se encuentra por encima del promedio regional.
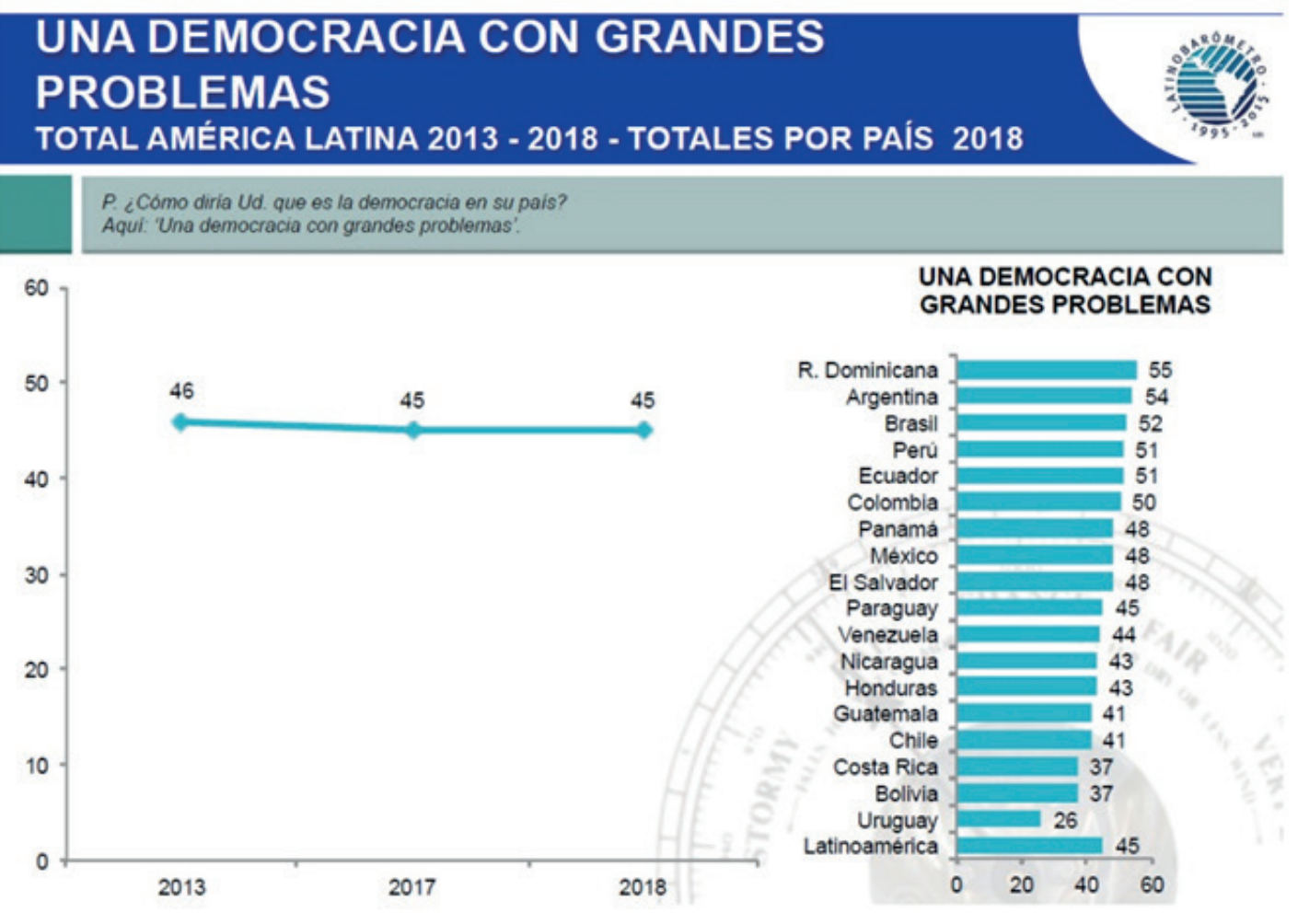

Figura 4. Perú: una democracia con grandes problemas

Fuente: Latinobarómetro (2019, p. 34)

18 Resulta interesante que durante el gobierno de Humala (2011-2016) se acuñó el adagio de "continuar con el piloto automático en materia económica" (Vergara, 2013). Dicha creencia de conservar la economía en ese "piloto automático" fue compartida por varios de los candidatos en las últimas elecciones. La importancia de una creencia de este tipo sitúa al gobierno con menor poder, al menos en materia económica, como si esta solo fuese posible de ser manejada por especialistas (¿élite académica o empresarial?). 
Esta paradoja de la democracia con grandes dificultades que no produce satisfacción ante la percepción pública son mediciones que permiten observar la fragilidad del sistema democrático peruano. Lo que queda como una investigación pendiente es encontrar el grado de relación entre un gobierno y la alteración del sistema político en su conjunto.

La figura 5 resulta ilustrativo para reconocer la incertidumbre por las preferencias electorales de la ciudadanía si las elecciones fueran en un plazo muy breve. Esta incertidumbre pone de manifiesto la desconfianza del sistema de partidos y del sistema político peruano mismo que actualmente enfrentó una situación atípica de adelanto de elecciones debido a una disolución constitucional del parlamento. Nuevamente el Perú se halla por encima del promedio regional y superado sólo por Guatemala, lo que representa un dato alarmante por los efectos en el sistema político en general.
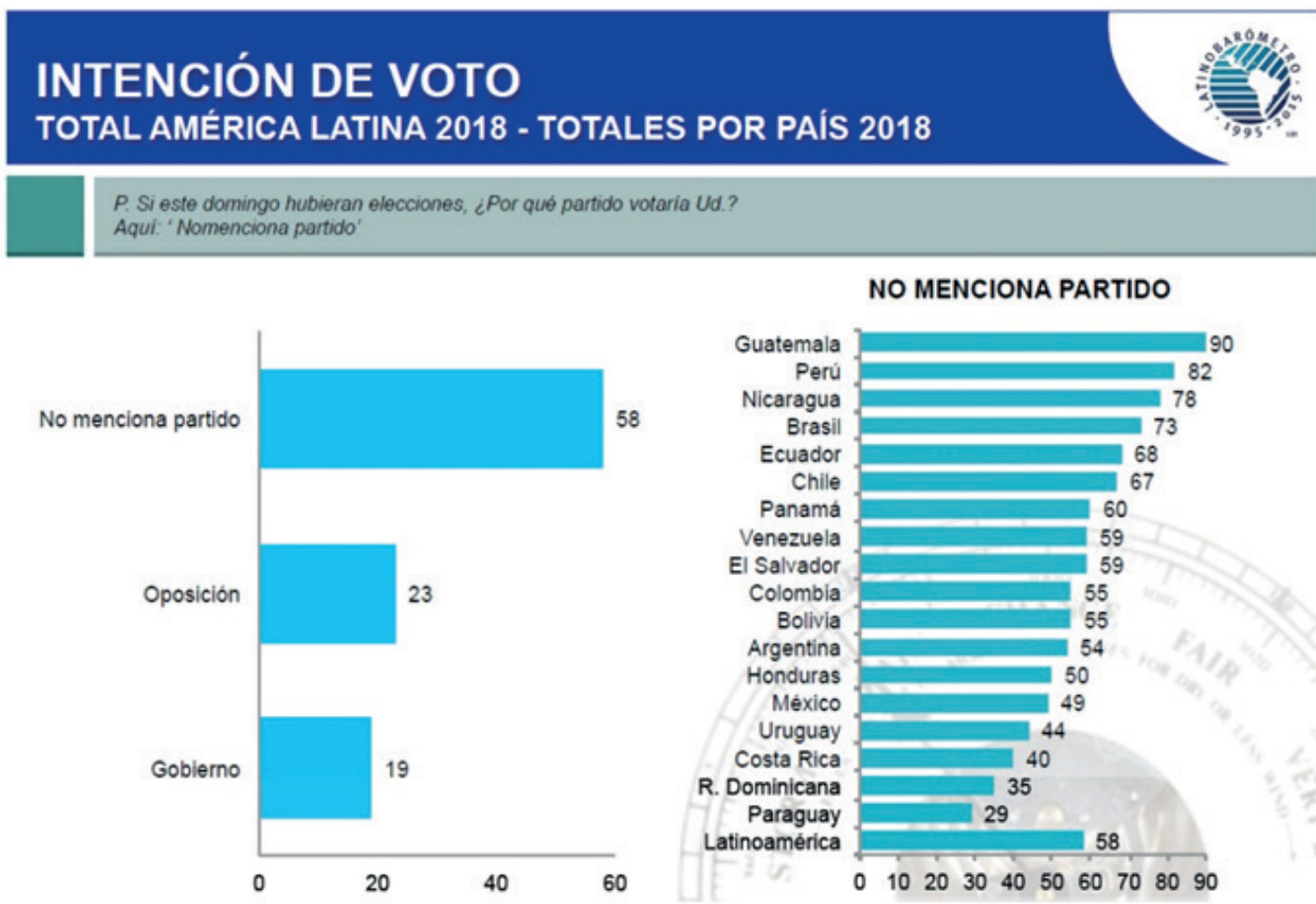

Figura 5. Intención de voto por país en América Latina (2018)

Fuente: Latinobarómetro (2019, p. 21)

En líneas generales, esto nos sugiere el carácter impredecible de las preferencias electorales y por ende la fragilidad de la dinámica política partidaria en tiempos electorales, con peligrosos efectos en tiempos de ejercicio del poder.

Por otra parte, la satisfacción general con respecto al sistema democrático no parece muy alentadora porque, en términos de opinión pública, sólo un $11 \%$ del sondeo se manifiesta como muy satisfecho y más bien satisfecho con el funcionamiento de la democracia. La figura 6 nos muestra que el Perú se halla muy por debajo del promedio regional, ocupando el segundo lugar en insatisfacción con la democracia. 


\section{SATISFACCIÓN CON LA DEMOCRACIA} TOTALES POR PAIS 2018

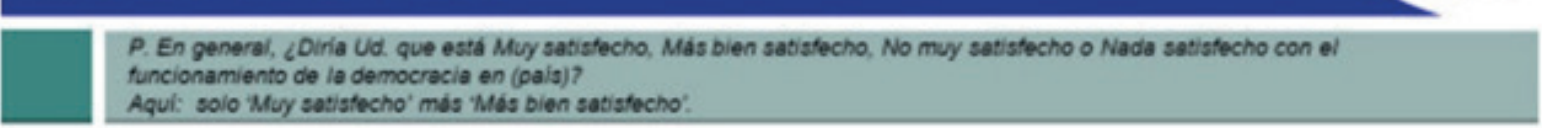

funcionamiento de le democracia en (paig)?
Aquil: solo 'Muy sosisfecho' mis 'Mds bien sabisfocho:

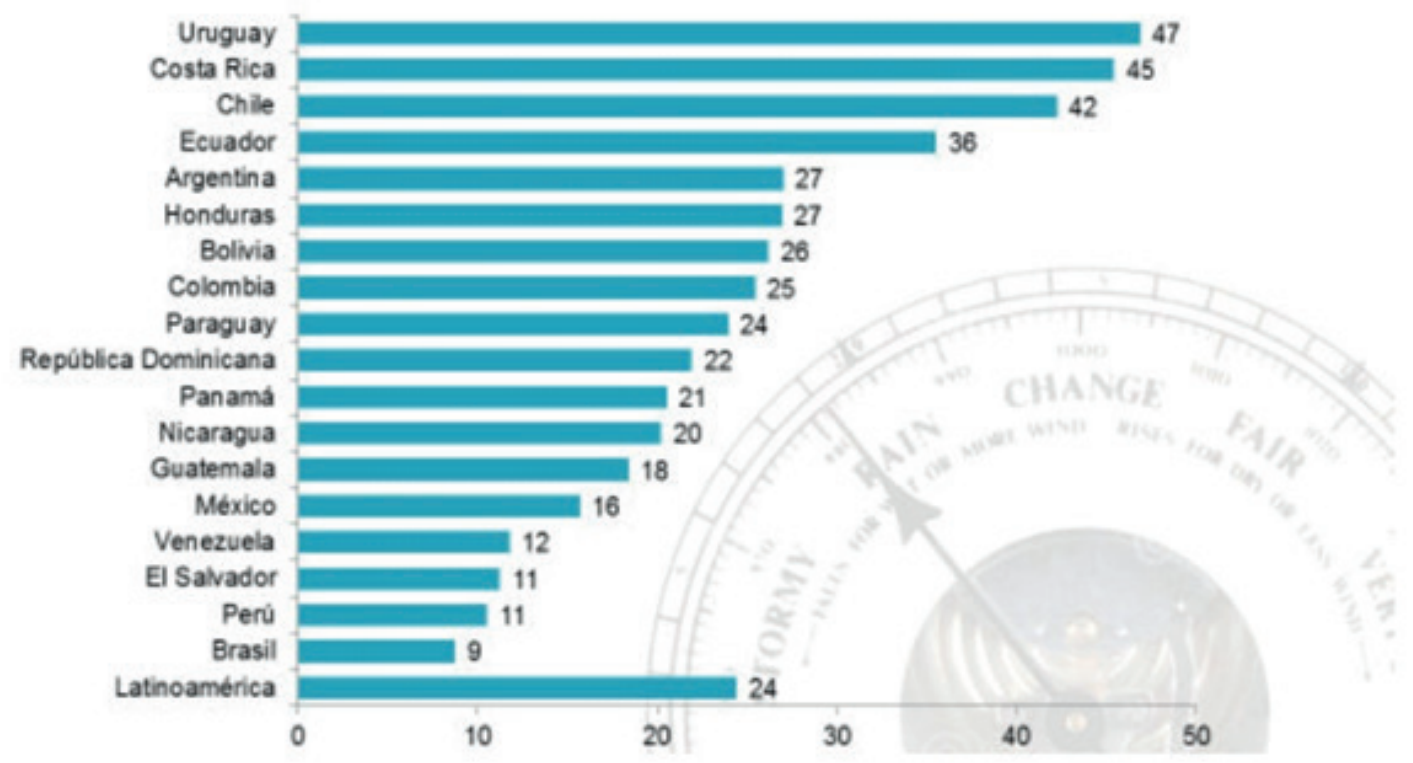

Figura 6. Satisfacción por países en Latinoamérica (2018)

Fuente: Latinobarómetro (2019, p. 35)

Finalmente, Transparency International nos ofrece reportes anuales sobre la percepción de la corrupción, utilizando para la medición diversas fuentes especializadas en los estudios del Estado y del sector privado. Para efectos comparativos, la tabla 5 nos presenta los datos del CPI score y el ranking mundial de tres años, pero usando la muestra completa del continente americano. Al respecto, podemos notar que el Perú tiene un CPI score más cercano al de países con alta percepción de corrupción como Venezuela, aunque en el ranking mundial nos ubicamos dentro del espectro medio.

El CPI score del Perú en tres años consecutivos no varía mucho, pese al escándalo político de la región latinoamericana a causa de los actos de corrupción de la Constructora Odebrecht y del anterior escándalo de los Panama Papers. Esto podría sugerir que la percepción de la corrupción en el Perú ya se halla en un límite mínimo y que los escándalos de corrupción regional sólo refuerzan esta percepción, sin incrementarla, porque ya se encuentra generalizada. Esto implica una investigación empírica que haga ampliaciones sobre la percepción de la corrupción. Pero, a partir de estos reportes, el Perú nuevamente se halla muy por encima del promedio mundial y regional sobre percepción de la corrupción. La tabla 5 nos permite reconocer la cercanía del Perú a países como Venezuela y su lejanía de países como Canadá. 
Tabla 5. Perú en el ranking mundial de percepción de la corrupción (2017-2019)

\begin{tabular}{|c|c|c|c|c|c|c|}
\hline \multirow{2}{*}{ País/territorio de América } & \multicolumn{2}{|c|}{2017} & \multicolumn{2}{|c|}{2018} & \multicolumn{2}{|c|}{2019} \\
\hline & CPI score & $\begin{array}{l}\text { Ranking } \\
\text { mundial }\end{array}$ & CPI score & $\begin{array}{l}\text { Ranking } \\
\text { mundial }\end{array}$ & CPI score & $\begin{array}{l}\text { Ranking } \\
\text { mundia }\end{array}$ \\
\hline Venezuela & 18 & 169 & 18 & 168 & 16 & 173 \\
\hline Haiti & 22 & 157 & 20 & 161 & 18 & 168 \\
\hline Nicaragua & 26 & 151 & 25 & 152 & 22 & 161 \\
\hline Guatemala & 28 & 143 & 27 & 144 & 26 & 146 \\
\hline República Dominicana & 29 & 135 & 30 & 129 & 28 & 137 \\
\hline Honduras & 29 & 135 & 29 & 132 & 26 & 146 \\
\hline México & 29 & 135 & 28 & 138 & 29 & 130 \\
\hline Paraguay & 29 & 135 & 29 & 132 & 28 & 137 \\
\hline Ecuador & 32 & 117 & 34 & 114 & 38 & 93 \\
\hline Bolivia & 33 & 112 & 29 & 132 & 31 & 123 \\
\hline El Salvador & 33 & 112 & 35 & 105 & 34 & 113 \\
\hline Brasil & 37 & 96 & 35 & 105 & 35 & 106 \\
\hline Colombia & 37 & 96 & 36 & 99 & 37 & 96 \\
\hline Panamá & 37 & 96 & 37 & 93 & 36 & 101 \\
\hline Perú & 37 & 96 & 35 & 105 & 36 & 101 \\
\hline Guyana & 38 & 91 & 37 & 93 & 40 & 85 \\
\hline Argentina & 39 & 85 & 40 & 85 & 45 & 66 \\
\hline Surinam & 41 & 77 & 43 & 73 & 44 & 70 \\
\hline Trinidad y Tobago & 41 & 77 & 41 & 78 & 40 & 85 \\
\hline Jamaica & 44 & 68 & 44 & 70 & 43 & 74 \\
\hline Cuba & 47 & 62 & 47 & 61 & 48 & 60 \\
\hline Granada & 52 & 52 & 52 & 53 & 53 & 51 \\
\hline Santa Lucía & 55 & 48 & 55 & 50 & 55 & 48 \\
\hline Dominica & 57 & 42 & 57 & 45 & 55 & 48 \\
\hline San Vicente y las Granadinas & 58 & 40 & 58 & 41 & 59 & 39 \\
\hline Costa Rica & 59 & 38 & 56 & 48 & 56 & 44 \\
\hline Bahamas & 65 & 28 & 65 & 29 & 64 & 29 \\
\hline Chile & 67 & 26 & 67 & 27 & 67 & 26 \\
\hline Barbados & 68 & 25 & 68 & 25 & 62 & 30 \\
\hline Uruguay & 70 & 23 & 70 & 23 & 71 & 21 \\
\hline Estados Unidos de América & 75 & 16 & 71 & 22 & 69 & 23 \\
\hline Canadá & 82 & 8 & 81 & 9 & 77 & 12 \\
\hline
\end{tabular}

Fuente: Transparency International $(2018,2019,2020)$

\section{Conclusiones:}

1. La noción de democracia procedimental basado en el criterio de existencia o ausencia de elecciones resulta insuficiente para evaluar un sistema político. Los aportes de Tilly y Dhal, entre otros, resultan pertinentes para abordar criterios de contenido sobre los derechos civiles reconocidos y la relación entre gobiernos y opositores.

2. Se puede analizar la calidad de la democracia vista en un triple sentido: procedimiento, contenido y resultado. Tal como propone metodológicamente Morlino, esto sirve de 
base para evaluar el rendimiento del sistema político. A su vez, esto implica situar el rol del Estado en un lugar central, debido a su capacidad de dotar de instituciones, infraestructura, legalidad y contenido a la dinámica política, así como el reconocimiento de derechos sociales necesarios en países como el nuestro ${ }^{19}$.

3. El inicio del sistema político en la década de los 80 contiene una ampliación de ciudadanía que marcó un punto de inflexión, pero que aún mantiene pendiente otros criterios sustantivos como el del debate público, la desigualdad, la justicia, la corrupción y el reconocimiento de derechos a comunidades campesinas y amazónicas.

4. La experiencia de la democracia en el Perú se halla situada desde el 2001 en el retorno a la democracia procedimental o el entrampamiento del piloto automático que encierra no solo la conservación de los intereses de las élites, sino la misma estructura que da existencia a las mismas. Esto implica una dinámica de conflicto que se opone a una consolidación democrática y que se comprueba con los diferentes conflictos medioambientales de los últimos 19 años.

5. Se requieren estudios completos sobre las élites en el Perú y su rol en el Estado. La fortaleza del Estado para reprimir rápidamente protestas antes de generar mesas de diálogo, podría explicarse debido a la existencia de centros de poder, no solo con autonomía sino con gran capacidad para capturar el Estado, para determinar las líneas de gobierno y el fortalecimiento de regímenes liberales con estándares de la democracia procedimental desde el 2001 a la fecha.

6. En un sentido histórico, la noción de "transición hacia la democracia" resulta ambigua porque posterga el debate político -y también académico- sobre el contenido sustantivo de los derechos civiles más allá del derecho a voto. Es decir, aquellos derechos civiles relacionados con derechos sociales como el empleo, la seguridad personal, salud o educación, entre otros. Son estos derechos sociales los que requieren de una mayor atención del Estado, así como de políticas públicas que implican la apertura a las demandas de los diferentes grupos sociales. El reto de la democracia actual es fortalecer al Estado como dador de derechos sociales, de una infraestructura institucional.

7. El reto de la democracia actual es fortalecer al Estado como dador de derechos sociales y de una infraestructura institucional. Este fortalecimiento del rol central del Estado podría revertir las mediciones negativas con respecto a satisfacción con la democracia, preferencias electorales o percepción de corrupción que nos sitúan en una posición muy rezagada en comparación con el resto de países de la región.

\section{Referencias.}

Basadre, Jorge (1983). Historia de la república del Perú. Lima: Editorial Universitaria.

Cameron, Maxwell y Paolo Sosa (2013). "Organizaciones políticas no institucionalizadas y Estado de derecho en el Perú post-Fujimori: una propuesta para la investigación”. Politai: Revista de Ciencia Política, 4 (7): 89-106.

Crozier, Michel, Samuel Huntington y Joji Watanuki (1975). The crisis of democracy. Report on the governability of democracies to the Trilateral Comission. New York: New York University Press.

Dahl, Robert (2009). La poliarquía. Participación y oposición. Madrid: Editorial Tecnos.

Dahl, Robert (2012). La democracia. Barcelona: Editorial Planeta.

Diamond, Larry (2004). “Elecciones sin democracia. A propósito de los regímenes híbridos”. Estudios Políticos, (24): 117-134.

19 Para un estudio más sistemático véase Lynch (2009). 
Dumay, Jean-Michel. (2019). « La CGT à l'heure des «gilets jaunes». Débats au sein de la centrale syndicale à la veille de son congrès ». Le Monde Diplomatique, (782): 4-5.

Durand, Francisco (2004). El poder incierto. Trayectoria económica y política del empresariado peruano. Lima: Fondo Editorial del Congreso de la República.

Durand, Francisco (2016). Cuando el poder extractivo captura al Estado. Lobbies, puertas giratorias y paquetazo ambiental en Perú. Lima: Oxfam.

Durand, Francisco (2019). Odebrecht. La empresa que capturaba gobiernos. Lima: Pontifica Universidad Católica del Perú, Fondo Editorial.

Flores, Jorge. (2015). "Contexto de cambios y continuidades en el Perú a finales del siglo xx. El papel de la CONFIEP, en la modernización del estado". Aula y Ciencia, 7 (11): 191-211.

Giddens, Anthony. (2006). La constitución de la sociedad. Bases para la teoría de la estructuración. Buenos Aires: Amorrortu

Huntington, Samuel P. (1994). La tercera ola. Democratización a finales del siglo XX. Barcelona: Editorial Paidos.

Latinobarómetro. (2019). Informe Latinobarómetro 2018. Recuperado de: http://www.latinobarometro.org/lat.jsp

Levitsky, Steven y Lucas Way (2004). "Elecciones sin democracia. El surgimiento del autoritarismo competitivo". Estudios Politicos, (24): 159-176.

López, Sinesio. (1997). Ciudadanos reales e imaginarios. Concepciones, desarrollo y mapas de la ciudadanía en el Perú. Lima: Instituto de Diálogo y Propuestas.

Lynch, Nicolás. (2009). El argumento democrático sobre América Latina. La excepcionalidad peruana en perspectiva comparada. Lima: Fondo Editorial de la Facultad de Ciencias Sociales de la Universidad Nacional Mayor de San Marcos.

Mariátegui, José Carlos (1987 [1928]). Alma Matinal y otras estaciones del hombre de hoy. Lima: Empresa Editora Amauta.

Mayer, Enrique. (2017). Cuentos feos de la reforma agraria peruana. Lima: Instituto de Estudios Peruanos.

Mendoza, Raúl (02 de julio de 2011). Conozca las “patinadas” verbales de Alan García. Recuperado de: https:// larepublica.pe/politica/553595-conozca-las-patinadas-verbales-de-alan-garcia/

Michels, Robert (1991). Los partidos politicos. Buenos Aires: Amorrortu

Morlino, Leonardo. (2014). La calidad de las democracias en América Latina. Informe para IDEA Internacional. San José de Costa Rica: IDEA Internacional.

Morlino, Leonardo (2012). "Observando las diferentes calidades de la democracia”. Revista Mexicana de Análisis Político y Administración Pública, 1 (1):9-48.

Mosca, Gaetano. (2004). La clase política. México: Fondo de Cultura Económica.

O’Donnell, Guillermo (1994). "Delegative democracy”. Journal of Democracy, 5 (1): 55-69.

O’Donnell, Guillermo (2004). "Accountability horizontal: la institucionalización legal de la desconfianza política”. Revista española de Ciencia Política, (11): 11-31.

O’Donnell, Guillermo, Osvaldo Iazzetta y Hugo Quiroga (2011). Democracia delegativa. Buenos Aires: Prometeo Libros.

Pareto, Wilfredo (1980). Forma y equilibrio sociales. Madrid: Alianza Editorial

Pease, Henry (1977). El ocaso del poder oligárquico: Lucha política en la escena oficial. 1968-1975. Lima: DESCO

Quiroz, Alfonso W. (2013). Historia de la corrupción en el Perú. Lima: Instituto de Estudios Peruanos.

Soria, Daniel. (2015). "Las democracias con libertades disminuidas en Latinoamérica en el siglo XXI y la Carta Democrática Interamericana: ¿Dos modelos de democracia en la región?”. Revista de la Facultad de Derecho de la Pontificia Universidad Católica del Perú, (75): 57-74.

Tilly, Charles (2010). Democracia. Madrid: Ediciones Akal. 
Transparency International. (2018). Corruption Perceptions index 2017. Recuperado en: https://www.transparency. org/whatwedo/pub/corruption_perceptions_index_2017

Transparency International (2019). Corruption Perceptions index 2018. Recuperado en: https://www.transparency. org/whatwedo/publication/corruption_perceptions_index_2018

Transparency International (2020). Corruption Perceptions index 2019. Recuperado en: https://www.transparency. org/en/cpi/2019/press-and-downloads

Varios autores (2018). Gilets jaunes. Des clés pour comprendre. Recuperado en : www.syllepse.net/syllepse_ images/gilets-jaunes--des-cles-pour-comprendre.pdf

Vergara, Alberto (2013). Ciudadanos sin República. Lima: Editorial Planeta.

Presentado: 25 octubre 2019

Aceptado: 19 marzo 2020

Publicado online: 15 julio 2020 